\title{
ESPORTE CLUBE SÃO JOSÉ DE PORTO ALEGRE (RS): A BUSCA PELA SUA SEDE DEFINITIVA (1913-1940)
}

DOI: 105902/010283089219

Data de Submissão: 20/06/2013 Data de Aceite: 04/12/2013

\begin{abstract}
Ronaldo Dreissig de Moraes
Mestrando do Programa de Pós-Graduação em Ciências do Movimento Humano (PPGCMH) da Escola de Educação Física (ESEF) da Universidade Federal do Rio Grande do Sul (UFRGS) ronaldodreissig@yahoo.com.br

Carolina Fernandes da Silva

Doutoranda do Programa de Pós-Graduação em Ciências do Movimento Humano (PPGCMH) da Escola de Educação Física (ESEF) da Universidade Federal do Rio Grande do Sul (UFRGS) carol_ed.fis@hotmail.com

Janice Zarpellon Mazo

Professora Doutora do Programa de Pós-Graduação em Ciências do Movimento Humano (PPGCMH) da Escola de Educação Física (ESEF) da Universidade Federal do Rio Grande do Sul (UFRGS) janmazo@terra.com.br
\end{abstract}

RESUMO: O Esporte Clube São José foi fundado em 1913, pela iniciativa de estudantes do Colégio São José de Porto Alegre visando à prática do futebol. O clube migrou por diversos locais em Porto Alegre até adquirir em 1939 o terreno de sua atual sede. O objetivo da pesquisa é reconstruir as memórias do Esporte Clube São José, especificamente no que diz respeito a sua mobilidade espacial, desde sua fundação em 1913 até 1940, quando inaugurou o estádio próprio. As fontes analisadas foram o livro comemorativo do clube, reportagens de jornais e revistas. Percebeu-se que as trocas constantes de sede do clube estão relacionadas com o processo de urbanização de Porto Alegre. A expansão da cidade influenciou na troca de sedes e na própria organização do clube, já que ficaram cada vez mais disputados espaços com grande área, como campos de futebol, pela construção civil.

Palavras-chave: Futebol. Clube. História do Esporte. 


\section{Introdução}

O Esporte Clube São José foi fundado em maio de 1913 pela iniciativa de estudantes católicos do Colégio São José. Os jovens estudantes criaram a Sociedade Juventude dos Moços Católicos, uma associação que tinha entre suas finalidades promover a prática do futebol nas dependências do colégio, situado ao lado da Igreja São José, na antiga Rua São Raphael, atual Avenida Alberto Bins no Bairro Centro de Porto Alegre. Com o crescimento da associação e a dificuldade de encontrar adversários para jogar, os jovens decidiram fundar um clube de futebol independente (ESPORTE CLUBE SÃO JOSÉ, 2003).

Curiosamente houve a fundação do clube, mesmo sem ter uma sede própria. O "Zequinha", como o clube também ficou conhecido na cidade, utilizou uma série de locais em Porto Alegre até fixar-se na sua atual sede. Assim, a pequena associação de futebol cresceu e consolidou-se no cenário futebolístico sul-rio-grandense, profissionalizando o futebol. As dificuldades iniciais suscitadas pela ausência de uma sede própria e as demais que surgiram ao longo dos anos foram superadas pelo clube, que no ano de 2013 comemora seu centenário.

O objetivo da pesquisa é reconstruir as memórias do Esporte Clube São José, especificamente no que diz respeito a sua mobilidade espacial, desde sua fundação em 1913 até 1940, quando inaugurou o estádio próprio.

Esta investigação se caracteriza pela utilização de fontes impressas, tais como: a revista comemorativa de 90 anos do clube (ESPORTE CLUBE SÃO JOSÉ, 2003), reportagens do jornal Correio do Povo de 1913 a 2003, guardadas no arquivo do Esporte Clube São José, reportagens do Catálogo do Esporte e da Educação Física da Revista do Globo, elaborado por Mazo (2004). As informações obtidas foram submetidas à análise documental, de acordo com Bacellar (2005). Além disso, foi realizada uma revisão bibliográfica em livros, artigos científicos, dissertações e teses visando abordar o contexto histórico da cidade no recorte temporal deste estudo.

Este estudo histórico estabelece conexões com a Geografia Cultural e a Geografia dos Esportes, um dos campos de investigação da Geografia Cultural. Para Corrêa (1995) a Geografia Cultural está baseada na subjetividade, na intuição, nos sentimentos, na 
experiência e no simbolismo, privilegiando o singular e não o particular ou o universal. Mascarenhas (1999) considera que a Geografia dos Esportes assume papel importante para a compreensão do fenômeno esportivo. No que tange à configuração territorial, os esportes merecem a observação cuidadosa dos geógrafos e pesquisadores, posto que sua prática implica transformações significativas na forma e na dinâmica territoriais. A geografia cultural está focalizada na interpretação das representações que os diferentes grupos sociais construíram a partir de suas próprias experiências e práticas, quando se busca analisar as representações que os atores do cenário esportivo fazem do espaço onde vivem, o estudo está inserido no campo de estudos da geografia cultural (CORRÊA, 2009).

Julgou-se necessário sustentar a pesquisa nessa abordagem teórica devido ao processo de mobilidade espacial que o Esporte Clube São José ao longo de quase 40 anos de existência. Paul Claval (2002) defende que o espaço jamais aparece como algo neutro na vida dos indivíduos e dos grupos, pois resulta da ação humana, que transformou a realidade natural, ao criar paisagens humanas e humanizadas. "Os lugares e as paisagens fazem parte da memória coletiva. A lembrança do que aconteceu no passado dá forte valor sentimental a certos lugares" (CLAVAL, 2002, p. 24).

Denis Cosgrove (1998) nos indica que devemos pensar uma nova geografia que ultrapasse os limites de um funcionalismo utilitário de forças demográfico-econômicas para operar em outras lógicas e motivações humanas, que produzem paisagens repletas de significados. Nessa perspectiva é que se introduzem os esportes na reflexão e análise geográficas. Pensando nesses significados construídos, relacionados com o sentimento de pertencimento, Christopher Gaffney (2008) nos indica que os estádios nos são importantes por serem lugares que nos possibilita compartilhamos nossas emoções em comum, em um lugar comum, e em um limitado espaço de tempo.

No caso desse estudo, os estádios de futebol recebem destaque, já que são equipamentos fixos na paisagem e geralmente de grande porte físico, o que resulta em maior capacidade de permanência. São também objetos de grande visibilidade na paisagem urbana, podendo ainda, constituir importante centralidade física e simbólica no interior do espaço urbano (MASCARENHAS, 1999). 


\section{A peregrinação do Esporte Clube São José em busca de uma sede}

O Esporte Clube São José foi fundado em 24 de maio de 1913, por ação de um grupo de jovens católicos que frequentavam a ex-Capela São José, que é localizada na antiga rua São Raphael (atual Avenida Alberto Bins), no centro de Porto Alegre (ESPORTE CLUBE SÃO JOSÉ, 2003). Antes disso, estes adolescentes estavam abandonando os atos religiosos e sociais da igreja para praticar o futebol.

A Capela São José foi criada por imigrantes alemães que frequentavam a Igreja Nossa Senhora do Rosário. Como não foram bem recebidos por essas e outras comunidades religiosas devido ao seu comportamento expansivo, criam um núcleo independente, em janeiro de 1871, como forma de manutenção de sua identidade. Somente em 1924 a Capela se transformou em Igreja São José, cujo projeto arquitetônico foi idealizado pelo imigrante alemão Joseph Lutzenberger, reconhecido como um grande arquiteto na cidade de Porto Alegre (VARGAS, 2004).

Com o propósito de mantê-los perto da comunidade católica, e com o incentivo de um dos líderes dessa associação, o Irmão Constantino, os jovens são convidados a participar da Sociedade Juventude dos Moços Católicos. Nesta associação, através da criação de um departamento, foi permitida a prática do futebol no Colégio São José, que ficava situado ao lado da igreja. Entretanto, como o grupo não podia enfrentar equipes fortes e o departamento da Sociedade Juventude dos Moços Católicos não atingiu o objetivo de manter os adolescentes nas atividades da igreja, em setembro de 1913, o clube se dissolve da sociedade.

Entre os jovens fundadores do clube estavam José Edgar Vielitz, Osvaldo Endler, Florêncio Wurding, Léo De La Rue, Antônio Pedro Netto e Arnaldo Peterlongo Ely. Por aparentar ser o mais vigoroso dos jovens, Léo De La Rue foi escolhido o primeiro presidente do clube. Na sua primeira ação administrativa estabeleceu que cada jogador comprasse o seu uniforme e contribuiria com um valor mensal para a manutenção da equipe (A ODISSÉIA, 1943). Devemos ressaltar que desde sua fundação, em 1913, até 1940, no ano de inauguração de seu estádio atual o clube migrou por diversos espaços de Porto Alegre, não permanecendo muito tempo em um mesmo local. Na sequência, analisaremos cada uma das sedes, abordando os acontecimentos do clube e o contexto da cidade de Porto Alegre. 


\section{Campo da "Montanha"}

Os registros encontrados sobre o clube no período da sua fundação são escassos. Além disso, em 1913 existia, na cidade de Canoas, uma equipe de futebol denominada Sport Club Canoense, que era formado em grande parte por alunos do Collegio São José, situado nessa mesma cidade. Esse fato causou um equívoco do clube na catalogação das reportagens extraídas do Jornal Correio do Povo, considerando os dois clubes como uma mesma entidade (CORREIO DO POVO, 29/07/1913 - 26/08/1913). Contudo, o confronto de fontes históricas permitiu elucidar alguns acontecimentos.

No ano da fundação, o primeiro espaço utilizado pelo Esporte Clube São José foi a Chácara do Coronel Germano Petersen. O campo ficava situado na área onde hoje funciona o Hospital Militar, na Avenida Cristóvão Colombo, esquina com a Avenida Mariland, no Bairro Auxiliadora. O relato de Léo De La Rue, presidente do Esporte Clube São José nos anos de 1913 e 1914, publicado na Revista do Globo em 1943, relembra os primeiros anos do clube: "todos os domingos e feriados rumávamos para a Chácara do Cel. Germano Petersen, onde improvisávamos um campo e lá ficávamos batendo bola... Os primeiros jogos foram um desastre; nem é bom falar..." (A ODISSÉIA, 1943, p. 36). Neste depoimento, também é possível identificar aspectos da organização do clube e equipe de futebol no período inicial, que no início contava com as mensalidades dos esportistas se para manter, "quinhentos réis pagávamos por mês para o clube, sendo a renda mensal, portanto, de 15 cruzeiros, como se diz hoje. E chegava. O tesoureiro era econômico e uma bola naquele tempo durava uma eternidade" (A ODISSÉIA, 1943, p. 36).

Pensando no contexto histórico da cidade de Porto Alegre, a capital do Rio Grande do Sul vivia um momento de transformações acentuadas. Na transição do século XIX para o século XX, ocorreu a consolidação do Partido Republicano Rio-Grandense (PRR) no poder e, conforme Monteiro (2004), José Montaury assumiu em 1897, a Intendência de Porto Alegre. A continuidade do PRR na administração local e desse intendente no poder, entre 1897 e 1924 marcariam o processo inicial de urbanização de Porto Alegre. Ainda segundo o autor, além dessa nova configuração política, a cidade teve um aumento no crescimento populacional e o início do processo de industrialização. Na última década do século XIX, 
a taxa de crescimento demográfico ao ano cresceu de 2,5\% em 1890 para 3,4\% em 1900. Nesse ano a população era de 73.474 habitantes em Porto Alegre (MONTEIRO, 2004, p. $52)$.

No contexto de surgimento do Esporte Clube São José, Porto Alegre teve uma expansão predial em ritmo intenso de 1903 até 1912. Em 1902, a cidade possuía 235 novos prédios licenciados (16.624 m2 de área). Já em 1912, contabilizava 1.590 novos prédios (área de 104.492 m2). Nesse intervalo de tempo, 6.060 prédios são licenciados, o equivalente a uma cidade nova, considerando a Porto Alegre do final do século XIX. Após esse período, entre 1912 e 1913, embora com pequena queda, o ritmo de construções se mantém acelerado. Mas deste momento em diante, o movimento de construções caiu sensivelmente por seis anos, como provável reflexo da Primeira Guerra Mundial (FRANCO, 2000). Para o autor, parece haver uma estreita relação entre o licenciamento de novos prédios e os momentos de prosperidade ou de depressão econômica (FRANCO, 2000).

O Campo da "Montanha" era um espaço que o Coronel Germano Petersen emprestava aos jogadores do São José (A ODISSÉIA, 1943). Ele possivelmente frequentava a Igreja São José no centro de Porto Alegre. Além disso, há registros em algumas escalações da equipe do sobrenome "Petersen", o que nos leva a pensar que Germano Petersen ou um familiar jogavam pelo clube. O terreno era um espaço plano de dimensões reduzidas. Nas suas adjacências, o terreno se tornava irregular e com vegetação. Devido a essas características, pressupõe-se que o espaço fora considerado inadequado para a prática do futebol, o que motivou o clube a buscar novo local para realizar suas partidas.

\section{Ground Navegantes}

O Esporte Clube São José começa a utilizar seu segundo espaço de jogo no dia 07 de junho de 1914, dia de seu primeiro aniversário. O jornal Correio do Povo relatou as pretensões futebolísticas do clube para o ano: "inaugurar seus players, jogando uma série de matchs com os principaes clubs locaes" (CORREIO DO POVO, 26/05/1914, s/p), esta nota jornalística destacou o planejamento de mudanças espaciais do clube para aquele ano, que ocupava, provisoriamente, "o ground junto á chácara do coronel Germano Petersen 
[...]. Este club festejará o anniversario e inaugura o ground proprio, situado á rua $\mathrm{S}$. José $\mathrm{n}$. 60, Navegantes, domingo, 7 de junho (CORREIO DO POVO, 26/05/1914, s/p).

Esse fragmento extraído do Correio do Povo é importante por ser um dos poucos registros encontrados sobre essa sede. Além disso, a reportagem fala sobre "ground proprio", o que implica pensar que essa área foi adquirida por algum valor. Essa informação pode abalar a hipótese de que a migração espacial do Esporte Clube São José foi fruto da falta de condições financeiras dos jovens para comprar um terreno. Entretanto, outra interpretação para essa reportagem é que o "ground proprio" refere-se a uma área não emprestada, como era o caso da Chácara do Coronel Germano Petersen. Sendo possível cogitar que o terreno do Bairro Navegantes não fosse propriedade do clube, já que nessa época era recorrente a apropriação de espaços vazios da cidade.

O Bairro Navegantes foi uma das primeiras regiões de Porto Alegre localizada fora do eixo central da cidade. O bairro teve início com a chegada de imigrantes alemães em Porto Alegre. A maioria desses integrantes eram artesãos e permaneceu nessa região devido à proximidade com a grande área de consumo, a região central de Porto Alegre, ligados pela Rua Voluntários da Pátria (FRANCO, 2000; PORTO ALEGRE, 2010). Neste local se localizava a maioria dos clubes de remo existentes no período (SILVA, MAZO, 2009; SILVA, 2011; SILVA; MAZO, 2012).

Esta localidade era uma importante região industrial da cidade, apesar disso, não recebeu recursos para sanar os problemas de alagamento e de saneamento básico (SILVA, 2009). Foi justamente em razão de um alagamento que o clube decidiu mudar do "Ground Navegantes", pois a enchente que atingiu o bairro acabou destruindo as instalações do clube. A equipe voltou a jogar na "Montanha" após esse fato (ESPORTE CLUBE SÃO JOSÉ, 2003). Nos registros encontrados sobre o São José, não se tem a data específica quando o clube retornou para a "Montanha", mas em maio de 1915, a equipe já jogava novamente na Chácara do Coronel Germano Petersen (CORREIO DO POVO, 25/05/1915, p. 3).

Quando o clube comemorou seu quarto aniversário de fundação, o jornal Correio do Povo, noticiou que o número de sócios excedia trezentos e tinha conquistado vitórias em dois campeonatos. Segundo o jornal, no ano de 1916 "o seu $2^{\circ}$ team foi o vencedor do campeonato da $4^{a}$ divisão da Associação de Foot-Ball Porto Alegrense. No anno seguinte 
coube ao $1^{\circ}$ team a victória do campeonato da $2^{a}$ divisão, instituido pela Federação Sportiva Rio Grandense (CORREIO DO POVO, 24/05/1917, p. 4 ). O clube comemorou estas conquistas ainda no Campo da "Montanha". Porém, em março de 1919, quando seu próximo espaço de jogo ficou pronto, seu destino foi o Bairro Floresta.

\section{Estádio da Bacia}

É provável que os primeiros treinos realizados no Estádio da "Bacia” tenham ocorrido em março de 1919. O campo de jogo ficava localizado no Bairro Floresta, ao lado da Igreja São Pedro. Foi uma área emprestada pelo Sr. Vicente Fernandes, torcedor do clube. Conforme consta na reportagem, em julho de 1918, o clube se empenhava para terminar as obras do seu campo: "A directoria do "Sport Club São José" está sériamente empenhada para que as obras no terreno adquirido para servir de "ground" desse club sejam concluídas no proximo mez de agosto" (CORREIO DO POVO, 18/07/1918, p. 3). O novo "ground" se situava na rua Christovão Colombo, ao lado da praça de São Pedro. Para a inauguração, o clube dispendeu, somente para o nivelamento do terreno, a quantia de quatro contos de réis (CORREIO DO POVO, 18/07/1918).

Mas os jogos só começaram a ser realizados na "Bacia” em abril de 1919, conforme reportagem do Correio do Povo: "Ainda este mez os sócios do "Sport Club São José" poderão iniciar os seus "trainings" no novo "ground" da Floresta." (CORREIO DO POVO, 11/03/1919). Finalmente em abril de 1919, a "Bacia" é utilizada de forma oficial: "O 'Sport Club S. José', depois de tantos annos de existencia, sómente agora é que vê realisada a sua maior aspiração, que é o possuir um ground perfeitamente adaptado ao jogo de football” (CORREIO DO POVO, 08/04/1919, p. 4). Essa fundação desenvolveu um imaginário, de que "com esse melhoramento uma grande victoria para a sua emancipação no foot-ball" (CORREIO DO POVO, 08/04/1919, p. 4). Nesse período pós-inauguração da "Bacia”, em quase todos os jogos registrados, o clube aplica diversas goleadas em seus adversários. Entre elas: 6 a 1 contra o Porto Alegre; 6 a 3 contra o Municipal; 6 a 1 contra o Tabajara; 10 a 4 contra o Concórdia; 11 a 1 contra o Concórdia (CORREIO DO POVO, 15/07/1919; 14/10/1920; 02/11/1920). 
No início da década de 1920, as atividades sociais estão cada vez mais presentes. A maioria das reuniões e festas do clube acontece na Sociedade Leopoldina Porto Alegrense (atual Associação Leopoldina Juvenil) ou na Chácara do Coronel Germano Petersen. Sempre com público superior a 80 pessoas nos compromissos sociais, em janeiro de 1921 a diretoria do clube aluga um espaço perto da "Bacia" para ser sua sede social. O fato foi noticiado no Jornal Correio do Povo do dia 20 de janeiro de 1921: "A directoria do Sport Club S. José, acaba de arrendar á rua Christovão Colombo, próximo a á sua praça desportos, um confortável prédio, afim de ali installar a sua sede social" (CORREIO DO POVO, 20/01/1921, p. 5 ).

As informações obtidas não são suficientes para afirmar, todavia, aparentemente o clube vivia um momento próspero, pois realizava suas festividades com boa presença de sócios, havendo inclusive a participação feminina no clube, os resultados em campo eram razoáveis e as camisetas utilizadas pelo clube eram trazidas de São Paulo.

O clube atinge 624 sócios ativos, número mais alto até então, no ano de 1923. Entretanto, em 1924 o número de sócios cai para 529 e, no ano de 1925, o clube termina o campeonato municipal em quinto lugar. Ficando atrás do Grêmio Foot-Ball Porto Alegrense, Sport Club Internacional, Sport Club Cruzeiro e Fuss Ball Club Porto Alegre. Em sexto lugar ficou o Sport Club Americano (CORREIO DO POVO, 27/11/1925, p. 4).

Acontece um dos episódios mais marcantes da história do São José No ano de 1927, o clube torna-se a primeira equipe sul-americana a viajar de avião para a realização de uma partida de futebol. O vôo até a cidade de Pelotas durou cerca de duas horas e meia. A idéia partiu do Diretor de Futebol Edgar Vielitz e do Secretário Moisés Antunes da Cunha. O Esporte Clube Pelotas aceitou pagar as despesas com a hospedagem e com o avião. Nesse ano de 1927, em maio, surgia a Viação Aérea Rio-Grandense (Varig), responsável por levar a delegação do São José, através do Hidroavião "Atlântico" (ESPORTE CLUBE SÃO JOSÉ, 2003; CAMPELO, 2005; CORREIO DO POVO, 07/06/1927; 12/06/1927).

Dois problemas causaram preocupação antes do hidroavião decolar das águas do Guaíba. Um dizia respeito ao tempo, que estava chuvoso, o outro, era referente ao excesso de peso. A Varig solicitou o peso exato de todos os jogadores para obter o melhor desempenho do hidroavião. Contudo, pronto para a decolagem, o comandante constatou 
que havia excesso de peso, já que os pesados casacos de lã dos jogadores não haviam sido incluídos na pesagem. Além disso, o hidroavião tinha somente nove poltronas, o que fez com que outros dois jogadores viajassem no compartimento de bagagens. Como todos os jogadores queriam sentir a sensação de voar, o comandante acordou que se o hidroavião decolasse sem problemas, a viagem seguiria com todos os passageiros. Antes da tentativa de deixar as águas do Guaíba, o presidente do clube, Waldemar Zapp, solicitou que fosse tirada uma foto de todo o grupo para guardar de lembrança, caso ocorresse uma tragédia. O hidroavião decola e chega a Pelotas no horário previsto. O jogo em Pelotas acabou terminando empatado em 2 a 2 (ESPORTE CLUBE SÃO JOSÉ, 2003; CAMPELO, 2005; CORREIO DO POVO, 07/06/1927; 12/06/1927).

Na revista comemorativa dos 90 anos do clube (ESPORTE CLUBE SÃO JOSÉ, 2003), há uma informação de que o clube também utilizou um campo no então Bairro Caminho do Meio, na área onde atualmente funciona o Hospital de Clínicas de Porto Alegre. Entretanto, o clube somente realizou poucas partidas nesse espaço que era utilizado pelo Esporte Clube Rui Barbosa.

Ao olhar aos acontecimentos em Porto Alegre, percebe-se que a cidade passou por um período de queda da construção civil até 1920. Essa diminuição do crescimento predial da cidade pode ter contribuído com que o clube permanecesse um tempo razoável no Estádio da "Bacia" no Bairro Floresta, tendo em vista que, somente no ano de 1928, quando Porto Alegre atinge o ápice da taxa de crescimento predial, o São José deixa a "Bacia" em direção ao Arrabalde de São João. Com o incremento da especulação imobiliária, a área emprestada ao clube, onde estava localizado o Estádio da "Bacia" dá espaço à construção de um loteamento (FRANCO, 2000; ESPORTE CLUBE SÃO JOSÉ, 2003).

\section{Campo do Arrabalde São João}

Com a impossibilidade de continuar na "Bacia", no Bairro Floresta, o clube acaba se instalando no Bairro São João, corredor de passagem para a Zona Norte de Porto Alegre. Como destaca o trecho do Jornal Correio do Povo, o clube se reorganiza para melhorar o espaço de jogo: 
Em virtude de ter assumido cargo de membro da commissão de obras do campo adquirido em São João, solicitou demissão do cargo de capitão geral o sr. Edgar Vielitz, cujo cargo será exercido pelo desportista Waldemar Palhares, membro influente do São José (CORREIO DO POVO, 21/04/1928, p. 5).

Segundo as fontes consultadas, o clube já jogava no Campo do São João desde maio de 1928 (CORREIO DO POVO, 08/05/1928). Este campo ficava situado entre as Avenidas Benjamin Constant (trecho que agora se chama Assis Brasil) e a Eduardo Chartier, próximo do Cemitério Municipal São João.

A ocupação do Bairro São João foi impulsionada pela instalação do transporte coletivo, além da implantação do Aeroporto, na década de 1930 (PORTO ALEGRE, 2010). Além disso, a região foi escolhida para ser o espaço de construção de vilas operárias. Era uma região privilegiada por ser o elo de ligação entre o interior do estado e o centro de Porto Alegre, através de vias férreas (RIELLA, 2004).

A crise internacional de 1929, aliada ao processo revolucionário em curso no país, tornam as condições de sobrevivência da classe operária bastante difícil. A falta de alimentos e moradia desencadeia uma medida emergencial. A primeira delas afeta diretamente o clube. Em uma área da prefeitura de $37.350 \mathrm{~m} 2$, é construída a Vila que beneficiava os trabalhadores em transporte de carga, do seu instituto específico (IAPTC). Esses institutos, criados já no início do governo de Getúlio Vargas, eram vinculados ao Ministério do Trabalho e tinham como principal função garantir o atendimento previdenciário (RIELLA, 2004).

\section{Estádio Passo D’Areia}

Após esse longo processo de mobilidade espacial, o Esporte Clube São José se fixa no Bairro Passo D`Areia, na Zona Norte de Porto Alegre. Com seu estádio localizado na Avenida Assis Brasil, número 1200. O São José já utilizava a área do Passo D`Areia desde o final do ano de 1937, mas somente dois anos depois, em 1939, o clube conseguiu adquirir o terreno do estádio. Na época, o clube não possuía muitos recursos, só sendo possível a compra do terreno através de um negócio de ocasião e da doação financeira de dirigentes do clube.

A área onde atualmente fica o Estádio Passo D`Areia era de propriedade de Rubem Berta, braço direito de Otto Ernst Meyer, fundador da Varig. Rubem Berta planejava 
construir na área uma pista de pouso. No entanto, como na região já havia uma expansão imobiliária considerável, ocorreu uma discussão sobre a falta de segurança dessa futura pista de pouso. Diante disso, a área é colocada à venda. Em 1939, por um valor abaixo de mercado, os dirigentes do Esporte Clube São José compram e doam o terreno ao clube. Eram eles: Walter Raab, Edmundo Lamb, Manoel Osório da Rosa, Francisco Ivo Schuh, Salvador Vigna e Eduardo Luiz Zottmann, que era o presidente do clube nesse período.

Após a compra, os esforços dos dirigentes foram no sentido de arrecadar fundos para a construção do estádio. Foi feito um trabalho de terraplanagem no local, além da construção das arquibancadas de madeira. Os sócios foram colaboradores importantes na aquisição de material de construção. No dia 24 de maio de 1940 é inaugurado oficialmente o Estádio Passo D`Areia. O time do Grêmio Foot-Ball Porto Alegrense, na época tricampeão citadino, foi escolhido para ser o adversário na partida de estréia. A equipe visitante saiu vencedora pelo placar de 3 a 2 .

\section{Considerações Finais}

Com a realização desta pesquisa, é possível perceber que as trocas constantes de sede do clube se relacionam com o processo de urbanização de Porto Alegre, o que não quer dizer que o clube trocou de sede diversas vezes, unicamente por esse motivo. Provavelmente, diversos fatores tenham contribuído para que isso ocorresse. Uma hipótese que não pode ser confirmada nem refutada com a realização desta pesquisa, é referente às condições financeiras do clube. Como vimos, os fundadores do Esporte Clube São José eram muito jovens, o que nos leva a pensar que não teriam condições financeiras para comprar e construir uma sede logo de início.

O fluxo de migração espacial que o clube passou acompanhou o fluxo de expansão da cidade de Porto Alegre, mesmo que em alguns momentos um pouco atrasado. Além disso, a expansão habitacional influenciou na troca de sedes e na organização do Clube, já que ficaram cada vez mais disputados e valorizados espaços com grande área e sem construções, necessários para a prática do futebol de clubes. É possível perceber a expansão do transporte coletivo em todo o Bairro São João e Bairro Passo D`Areia em 
1928, justamente no período em que o clube migra para essas regiões da cidade.

Recentemente, no ano de 2011 o Estádio Passo D`Areia trocou a grama natural por grama artificial, sendo um dos primeiros estádios de futebol a ter esse tipo de gramado em partidas oficiais. No ano de 2013 o clube completa cem anos de existência, participando frequentemente de competições regionais e nacionais.

\section{Referências}

A ODISSÉIA do São José, In: MAZO, J. Z. O Esporte e a Educação Física na Revista do Globo: catálogo (1927-1967). Porto Alegre: FEFID/ PUCRS, [2004], v. 15, n. 342, p. 36, 26 de junho de 1943.

ASPIS, A. Futebol brasileiro: do início amador à paixão nacional. Porto Alegre: Evangraf, 2006.

BACELLAR, C. Uso e mau uso dos arquivos. In: PINSKY, Carla Bassanezi (org.). Fontes Históricas. São Paulo: Contexto, 2005.

CAMPELO, E. L. Futebol Gaúcho: Grandes times e craques inesquecíveis. Porto Alegre: Secretaria Estadual da Cultura do Rio Grande do Sul, 2005.

CLAVAL, P. "A volta do cultural" na geografia. Mercator: Revista de Geografia da UFC, Fortaleza, v.1, n. 1, p.19-28, 2002. Disponível em: <http://www.mercator.ufc.br/index.php/ mercator/article/view/192>. Acesso em: 23 de janeiro de 2013.

CORREAA, R. L. Espaço: um conceito-chave da Geografia. In: CASTRO, I. E.; GOMES, P. C. C.; CORRÊA, R. L. Geografia: conceitos e temas. Rio de Janeiro: Bertrand Brasil, 1995.

CORREAA, R. L. Sobre a Geografia Cultural. Instituto Histórico e Geográfico do Rio Grande do Sul. Porto Alegre, nov., 2009. Disponível em: <http://www.ingrgs.org.br/ contribuicoes/geografia_cultural.htm>. Acesso em: 23 de janeiro de 2013.

CORREIO DO POVO. Correio do Povo, Porto Alegre, 29 de julho de 1913.

CORREIO DO POVO. Correio do Povo, Porto Alegre, 26 de agosto de 1913.

CORREIO DO POVO. Correio do Povo, Porto Alegre, 26 de maio de 1914.

CORREIO DO POVO. Correio do Povo, Porto Alegre, 25 de maio de 1915.

CORREIO DO POVO. Correio do Povo, Porto Alegre, 24 de maio de 1917.

CORREIO DO POVO. Correio do Povo, Porto Alegre, 18 de julho de 1918. 
CORREIO DO POVO. Correio do Povo, Porto Alegre, 11 de março de 1919.

CORREIO DO POVO. Correio do Povo, Porto Alegre, 08 de abril de 1919.

CORREIO DO POVO. Correio do Povo, Porto Alegre, 15 de julho de 1919.

CORREIO DO POVO. Correio do Povo, Porto Alegre, 14 de outubro de 1920.

CORREIO DO POVO. Correio do Povo, Porto Alegre, 02 de novembro de 1920.

CORREIO DO POVO. Correio do Povo, Porto Alegre, 20 de janeiro de 1921.

CORREIO DO POVO. Correio do Povo, Porto Alegre, 27 de novembro de 1925.

CORREIO DO POVO. Correio do Povo, Porto Alegre, 07 de junho de 1927.

CORREIO DO POVO. Correio do Povo, Porto Alegre, 12 de junho de 1927.

COSGROVE, D. A geografia está em toda parte: cultura e simbolismo nas paisagens humanas. In: CÔRREA, R. L.; ROZENDAHL, Z. Paisagem, Tempo e Cultura. Rio de Janeiro: Ed.UERJ, 1998. p. 96-97.

ESPORTE CLUBE SÃO JOSÉ: 90 anos de paixão e glórias de um grande clube. Porto Alegre: Brasul, 2003.

FRANCO, S. C. Gente e espaços de Porto Alegre. Porto Alegre: Editora Universidade, 2000.

GAFFNEY, C. Temples of earthbound gods: stadiums in the cultural landscapes of Rio de Janeiro and Buenos Aires. Texas (EUA): U of Texas Press, 2008.

LOPES SOBRINHO, H. Futebol e reminiscências: relembrando o futebol do passado. Santa Maria: Grafos, 1989.

MASCARENHAS, G. A Geografia dos Esportes: uma introdução. Scripta Nova. Revista Electrónica de Geografia y Ciencias Sociales. Barcelona, n.35, mar., 1999. Disponível em: <http://www.ub.es/geocrit/sn-35.htm>. Acesso em: 23 de janeiro de 2013.

MASCARENHAS, G. A via platina de introdução do futebol no Rio Grande do Sul. Lecturas: Educación Física y Deportes, Buenos Aires, v. 5, n. 26, p.1-2, out., 2000. Disponível em: <http://www.efdeportes.com/efd26a/platina.htm>. Acesso em: 22 janeiro de 2013.

MAZO, J. Z. Revista do Globo (1929-1967): Catálogo do Esporte e da Educação Física. Porto Alegre: FEFID/ PUCRS, 2004.

MAZO, J. Z. et al. Associações Esportivas no Rio Grande do Sul: lugares e memórias. 
Novo Hamburgo: Feevale, 2012.

MONTEIRO, C. Porto Alegre no século XX: crescimento urbano e mudanças sociais. In: DORNELLES, B. (Org.). Porto Alegre em destaque: história e cultura. Porto Alegre: EDIPUCRS, 2004, p. 51-74.

MORAES, R. D. A odisséia do Esporte Clube São José de Porto Alegre (RS): a busca pela sua sede definitiva (1913-1940). Trabalho de Conclusão de Curso. Escola de Educação Física, Universidade Federal do Rio Grande do Sul, Porto Alegre, 2010.

PORTO ALEGRE. Secretaria Municipal de Cultura. Centro de Pesquisa Histórica. História dos Bairros de Porto Alegre. Disponível em: <http://www2.portoalegre.rs.gov.br/ spm/default.php?p_secao=128>. Acesso em: 22 de janeiro de 2013.

RIELLA, C. Vila do IAPI - pioneirismo urbano, cultura e contestação. In: DORNELLES, B. (Org.). Porto Alegre em destaque: história e cultura. Porto Alegre: EDIPUCRS, 2004, p. 233-243.

SILVA, N. G. Meio Século de Projetos Municipais para a Habitação Operária em Porto Alegre: A institucionalização da Periferia. Aedos: Revista do Corpo Discente do Programa de Pós-graduação de História, Porto Alegre, v. 2, n. 4, p.35-47, nov. 2009. Disponível em: <http://seer.ufrgs.br/index.php/aedos/article/view/10613>. Acesso em: 22 de janeiro de 2013.

SILVA, C. F.; MAZO, J. Z. Club de Regatas Vasco da Gama: o jogo das diferenças nas associações de remo. Revista Mineira de Educação Física, Viçosa, Edição Especial, n.1, p. 142-153, 2012.

SILVA, C. O remo e a história de Porto Alegre, Rio Grande do Sul: mosaico de identidades culturais no longo século XIX. Dissertação de Mestrado. Programa de Pós-Graduação em Ciências do Movimento Humano, Universidade Federal do Rio Grande do Sul, Porto Alegre, 2011.

SILVA, C.; MAZO, J. Grêmio de Regatas Almirantes Tamandaré: memórias da fundação do primeiro clube de remo "brasileiro" em Porto Alegre (1903-1923). Revista Arquivos em Movimento, v. 5, n. 2, 2009.

VARGAS, E. Torres da Província: História e Iconografia das Igrejas de Porto Alegre. Porto Alegre: Pallotti, 2004. 


\title{
SPORT CLUB SAN JOSE OF PORTO ALEGRE (RS): THE SEARCH FOR ITS DEFINITIVE HEADQUARTERS (1913-1940)
}

\begin{abstract}
The Sport Club São José was founding in 1913, for the initiative of students of the São José School, from Porto Alegre, aiming the soccer practice. The club migrated to various places in Porto Alegre until acquiring, in 1939, the land of its current headquarters. The analyzed sources had been the commemorative book of the club, articles from newspapers and magazines. It was perceived that the constant changes of headquarters of the club are related with the process of urbanizations of Porto Alegre. The expansion of the city influenced in exchanges of headquarters and the within organization of the club, as it became increasingly competitive spaces with great area, such as soccer fields and for the civil construction.
\end{abstract}

Keywords: Soccer. Club. History of Sport

\section{ESPORTE CLUBE SÃO JOSÉ DE PORTO ALEGRE (RS): LA BÚSQUEDA PARA SUS JEFATURAS DEFINITIVAS (1913-1940)}

RESUMEN: El Esporte Club São José fue establecido en 1913, porque la iniciativa de los estudiantes de la colegio São José de Porto Alegre que tiene como objetivo el práctico del fútbol. El migrou del club para los lugares diversos en Porto Alegre hasta adquirir en 1939 la tierra de sus jefaturas actuales. El objetivo de la investigación es reconstruir las memorias del Esporte Clube São José, específicamente en lo que dice su movilidad del espacio respecto, desde su fundación en 1913 hasta 1940, cuando inauguró el estadio apropiado. Las fuentes analizadas habían sido el libro conmemorativo del club, de los artículos periódicos de las noticias y de los compartimientos. Uno percibió que los intercambios constantes de las jefaturas del club están relacionados con el proceso de la urbanización de Porto Alegre. La extensión de la ciudad influenciada en el intercambio de jefaturas y la organización apropiada del club, puesto que habían sido espacios cada vez más disputados con gran área, como campos del fútbol, para la construcción civil.

Palabras-clave: Fútbol. Club. Historia del Deporte. 